\title{
Research Approach to University \\ Library Problems
}

\author{
INTRODUCTION BY ROBERT H. MULLER
}

UNIVERSITY LIBRARIES face many complex and difficult problems. Library administrators are continually called upon to make policy decisions to solve these problems. Again and again, as decisions have to be made, it appears that knowledge of essential facts and relationships is lacking. As a consequence, many decisions are made more on the basis of hunches, assumptions, and guesswork than on the basis of reliable knowledge.

There are practitioners who are cynical of the very idea of library science; they prefer to think of librarianship as an art, where one is guided primarily by intuition, instinct, or impulse. There are others who are more optimistic about the possibility of developing a body of knowledge to guide one in arriving at solutions in as rational a way as possible. The Committee on Research and Development of the University Libraries Section of ACRL is committed to the view that dispassionate rational analysis, systematic investigation, critical evaluation, comparative study, controlled experimentation, and similar activities subsumed under the heading "research" should be pursued, with greater vigor than is often the case, toward the end of providing a sounder basis for library policy determination.

One of the reasons more research is not being done is that library administrators have apparently not developed a regular habit of making a note of the occasions when they are frustrated by lack of reliable knowledge. As soon as a decision about a problematic situation has been reached, even in cases when one was painfully aware of this lack of
Dr. Muller is Associate Director of $\mathrm{Li}$ braries, University of Michigan.

knowledge or supporting data, one has a tendency to put it out of one's mind and swiftly move on to any number of other pressing problems. No record is kept of one's realization of the need for research, nor is the need communicated to anyone who might be in a position to remedy the situation. When a similar problem is encountered in another library, the same sequence of (1) frustration, (2) quickly arrived decision, and (3) prompt forgetting is likely to take place. The net effect of such sequences in different library contexts is that very slow progress is made toward supplying the missing data. If the identical problem is encountered with some frequency in different libraries, someone may take it upon himself to conduct a "survey" of practices, showing how libraries A, B, C, etc. solved the problem. Such surveys are often presented without sufficiently penetrating analysis or commentary, so that one is left with the impression that any one of a variety of solutions has equal justification, and that the reason for several libraries solving a more or less identical problem in different ways is that different "local conditions" call for different solutions. To provide such an explanation is much easier than conducting a tight comparative study of results in terms of, say, cost or quality or long-range advantage.

Simple though it may sound, the first requirement for progress in gaining increased knowledge about university li- 
brary operations is to promote the cultivation of the recording and communication habits on the part of library administrators. They must learn to make a record of the problems they encounter for which they do not find data which leads to an adequate solution. This is by no means an easy task. They must be as specific as possible in indicating what data were lacking and what insights they expected to gain from it. Once the problem has been defined and basic research has been specified, a clearinghouse should be established for the collection, sifting, reformulation, and communication of the needs of different university libraries to those who may be in a position to help fill the need. It is this clearinghouse function that a Committee on Research and Development can perform. It can make available to those interested in conducting or financially supporting research in university librarianship lists of clearly defined topics on which research should be done to help practitioners make their decisions on sounder bases than had been available previously.

Some three years ago, the R \& D Committee followed a different approach but found it relatively unproductive. A letter was written to a selected number of university library administrators, requesting that each send to the committee a list of topics deemed worthy of systematic investigation or study. The result was a list of over forty topics, most of which, upon close analysis by the members of the committee, failed to meet the requirements of sufficiently clear formulation indicative of the sort of data to be collected and brought to bear upon solutions. The problems tended to be stated in terms that were much too broad and ill-defined. The reason for this failure may lie in the problems proposed for study having probably been concocted in an armchair on the spur of the moment, rather than having sprung from an ac- tual situation still vividly in mind. Nevertheless, a few of the proposed topics did seem to warrant further attention by members of the committee, and four members volunteered to elaborate upon one each for the purpose of defining them clearly and indicating their dimensions. These outlines are presented here for the purpose of encouraging university librarians and library administrators to submit research proposals, either directly or through the ACRL executive secretary, to the committee immediately upon having become aware of the lack of reliable knowledge the existence of which might have been helpful in the evaluation or determination of policy.

Example No. 1: "Standards of Output in Cataloging and Acquisitions," by Felix Reichmann.

Example No. 2: "Measuring Library Use," by Ralph T. Esterquest.

Example No. 3: "Success and Failure in Library Use," by Andrew Eaton.

Example No. 4: "Attitudes of University Administrators toward Libraries," by John F. Harvey.

\section{STANDARDS OF OutPut IN Cataloging and AcQuisition}

Reliable production standards for the technical services have been discussed by the profession for many scores of years. Feared by some librarians and eagerly requested by others, they have never been satisfactorily calculated. It is now proposed that a scholarly investigation of this important question be made.

Such a study has to avoid two pitfalls:

1. Oversimplification. To combine the production statistics of a group of libraries and to calculate statistical relations either with the number of staff members or with the amount spent for library materials does not give a satisfactory solution. 
2. Bias. Although the results of the study will have important budgetary implications, the investigation has to be made without regard to applications.

It will be necessary to analyze the complex technical operations and to calculate and test the length of performance of various operations. Moreover, a simple addition of the individual costs will not meet our needs. The cost of an operation by itself is not a meaningful figure unless the end product is clearly defined.

Production standards have to be related to (1) working conditions, machines available, (3) routines prescribed, and (4) final product desired. Variations will have to be calculated according to the characteristics of the material to be processed. Some of these categories are: (1) language; (2) publication date: current, old, and rare; source of publication: commercial, private, or government; (4) country of publication; (5) bibliographical accuracy of order request; (6) subject; (7) entries available from bibliographical books: LC, NUC.-Felix Reichmann.

\section{Measuring Library Use}

In their efforts to indicate the volume of library use, librarians have traditionally reported such statistics as: books loaned for home use, number of reference questions asked, and number of interlibrary loans transacted. In recent years especially, these data have appeared less and less meaningful as true measures of library use and usefulness. It is clear, for example, that a book lent to a student and unopened by him cannot be regarded as having the same importance as a book borrowed by another reader who bases a major paper on it. Furthermore, the journal article, not charged out, but read within the library building (perhaps even in the book- stacks) may contribute in a major way to furthering an important research project.

Thus, the usefulness of a library cannot be measured properly by simple statistics of loans of two weeks. Even in the matter of justifying budget increases, the customary use measures are inadequate. A 20 per cent increase in homeuse loans may justify a modest increase in clerical personnel for filing loan records and mailing overdue notices, but it cannot be used to justify such major expense items as professional and administrative staff or the purchase of retrospective files of scientific journals. Statistics of reserve book loans have a direct relation to size of staff on the reserve desk and perhaps to the number of multiple copies of reserve books, but they influence not at all most of the items of the library budget that are really significant. Moreover, they are hardly a proper measure of the educational and research role of the library as "the heart of the university."

It is proposed that new measures of library use be discovered for academic libraries.

Such new measures should be meaningful in the context of modern library operations and modern concepts of academic library service. Many possibilities come to mind: If open-stack browsing is a valid "service" in a library, why not count browsers? Or time the duration of their browsing? If access to an array of learned journals is offered, why not measure in some way the reader-hours spent examining such journals?

It would seem desirable for academic libraries to have meaningful measures of those varied library services which are important and costly in today's library situation. These measures ought to be quantitative in nature, objectively arrived at, and reasonably simple for the public and the university administrator to understand.- $R$. T. Esterquest. 
Success AND FaILURE IN

\section{LIBRARY USE}

Reader satisfaction is the ultimate goal of library service. Yet librarians know relatively little about their ability to satisfy users' needs. We assume that most students find the library helpful in connection with their class assignments, term papers, etc., but we have little objective, factual information as to how successful they are in finding what the library has to offer, why some do better than others, and what the library can and should do to make their experience more rewarding.

What is needed is detailed analysis of student experience in using libraries. This analysis should focus on individual students and by means of case studies should supply information concerning (1) projects or assignments requiring library use, (2) how the student went about his search and what he actually found, (3) what he might have found with optimum success, and (4) why his efforts fell short of achieving maximum results.

The purpose of this study would be to throw light on the degree of success achieved, variations among students in results obtained, and the factors associated with success and failure in library use.

Among the factors which presumably affect library use and which might be studied in relation to student success and failure are:

1. Characteristics of students (scholastic aptitude and achievement, cultural background and interests, library orientation in high school, access to good public library facilities, etc.)

2. Building arrangements (open stacks, segregated quarters for undergraduates or lower division students, subject divisional organization, departmental libraries, etc.)

3. Staffing arrangements (provision of subject specialists, assignment of professional staff to evening and week-end hours, advisors at the public catalog, liaison with teaching faculty, etc.)

4. Library orientation and instruction programs (formal courses, printed handbooks and guides, use of films, sharing responsibility with English or other department, etc.)

5. Bibliographical apparatus (divided catalog, availability of shelf list, provisions for public access to collections not fully cataloged, availability of union catalog, etc.)

By carefully focused studies of such variables as these we should obtain a clearer understanding of student success and failure in library use.-Andrew Eaton.

\section{AtTitudes of University ADMinistrators TOWARD LIBRARIES}

Presidents, vice presidents, comptrollers, and deans could be studied on at least twenty-five public and private university campuses. The amount of graduate work and teaching experience might be noted for each administrator as well as his formal and informal relationship to the library, i.e., whether or not the director of libraries reports to him directly for policy or fiscal affairs, and the extent of his personal use of the library.

The researcher could conduct private interviews at which a confidential questionnaire would be completed. The following are sample questions, stated in general terms, which might be asked:

1. What particular library problems come to his attention? What are the library's chief weaknesses? Chief strengths?

2. To what degree is the library integrated into the academic program of the university? Is the library the "heart" of the university? Should the library staff members have faculty status? Do they?

3. How successful are the administra- 
tor's relationships with library staff members, especially with the director? Does he find these staff members cooperative? Competent? Does he have faith in the director's judgment?

4. Is the library budget poor, adequate, or good? Within its means, is the university generous in its budgetary treatment of the library?

5. What improvements does he sug- gest in library organization? Service? Public relations? Finance? Building?

In the same way, the library director's evaluation of the university administration could be ascertained. Does he feel that the administration understands the library's purposes and problems, is in sympathy with these purposes and is trying to carry them out?-John F. Harvey.

\section{More About Periodicals-A British View}

"THE NUMBER of scientific periodicals is constantly growing, and certain publishers in particular are issuing streams of new journals on every conceivable subdivision of science. Furthermore, eminent scientists lend their names to these journals as editors, or serve on the editorial boards, and the contents of the journals deteriorate after the first few issues. These periodicals are preserved mainly in libraries, yet these are asked exorbitant subscriptions in excess of those expected from individuals who purchase the journals "for their own use." This leads to certain irregularities, and librarians are extremely critical of these unorthodox and unethical tactics. Unfortunately, few librarians are permitted to decide which journals they house, and which subscriptions should be cancelled, but they can advise their committees. If librarians could take joint action over these, and certain other matters, unscrupulous publishers would have a greatly decreased market for their wares, and certain periodicals would vanish, without leaving serious gaps.

Possibly one solution would be the introduction of greater control over scientific periodicals by societies, universities and institutions, who would not necessarily publish the journals, but would sponsor them through reputable publishing houses. They might also control the output of their members by discouraging the publication of material adding nothing to our knowledge of the subject. This, however, is a matter for national, and even international consideration, but the current trend is towards the opposite direction. Publication is encouraged; the use of grants must be justified by the number of articles printed, and the work of a university department tends to be judged by the weight of its literary output. We are faced with a gigantic, suicidal pact, in which the advancement of science is hampered by the inability of research workers to trace new facts among the masses of literature that must eventually suffocate those in pursuit of true knowledge."-J. L. Thornton and R. I. J. Tully, Scientific books, libraries and collectors. (2d. ed. Library Assoc., 1962.) 